\title{
Kemanusiaan dalam falsafah hidup masyarakat Batak Toba
}

\author{
Yakobus Ndona ${ }^{\mathrm{a}, 1^{*}}$ \\ ${ }^{a}$ Program Studi Pendidikan Kewarganegaraan, Universitas Negeri Medan, Indonesia \\ ${ }^{1}$ yakobusndona@unimed.ac.id \\ * korespondensi penulis
}

\begin{abstract}
ABSTRAK
Kemanusiaan, zaman sekarang telah menjadi prinsip universal dalam membangun peradaban dunia. Indonesia telah menetapkan kemanusiaan sebagai salah satu sila dalam dasar negara. Kemanusiaan dalam Pancasila tidak bersumber dari pemikiran spekulatif filosofis tetapi dari nilai-nilai yang telah hidup dalam kebudayaan nusantara sejak ribuan tahun lalu. Kajian tentang kemanusiaan dalam berbagai kebudayaan nusantara akan membuat pemahaman terhadap prinsip kemanusiaan dalam sila kedua akan komprehensif dan mendalam. Tulisan ini hendak mengungkapkan pemikiran tentang kemanusiaan dalam budaya Batak Toba. Orang Toba memiliki prinsip kemanusiaan yang bersumber dari pemahaman tentang manusia yang bermartabat rajawi. Martabat luhur ini menuntut setiap orang diperlakukan secara adil dan bermartabat.
\end{abstract}

Kata kunci: kemanusiaan, martabat rajawi, Batak, Toba

\section{ABSTRACT}

These days, humanity has become a universal principle that is used in building world's civilization. Indonesia has put humanity in its national principle. Humanity in Pancasila did not come from philosophical speculative thought, but from those values that have been living in our culture since thousands of years ago. By studying humanity in our culture, we can have deep and comprehensive understanding about humanity in the second principle of Pancasila. This research aims to analyze the thought about humanity in the Batak Toba's culture. Toba people have humanity principle that comes from their understanding about human who have kingly dignity by nature. This noble trait requires everyone to be treated fairly and with dignity.

Keywords: humanity, kingly dignity, Batak, Toba

Copyright (C2018Universitas Ahmad Dahlan, All Right Reserved

\section{PENDAHULUAN}

Setelah tujuh puluh tahun lebih kemerdekaan, tragedi kemanusiaan di negeri ini seakan tidak pernah berakhir. Kemiskinan, ketidakadilan sosial, pelanggaran hak-hak asasi manusia, kebijakan yang diskriminatif, perbudakan yang lemah, perdagangan perempuan, perilaku intoleran dan banyak persoalan kemanusiaan masih terus menghantui warga negeri ini. Situasi ini menimbulkan pertanyaan tentang penghayatan nilai kemanusiaan.

Para pendiri bangsa telah menetapkan kemanusiaan yang adil dan beradab sebagai sila kedua dalam dasar negara. Penetapan ini membawa konsekuensi bahwa sila Pancasila harus menjadi nilai yang mendasari kehidupan masyarakat, kebijakan negara dan pembangunan nasional. Kesadaran ini harus menjadi memotivasi warga bangsa untuk terus mendalami sila kedua supaya semakin bergema dalam kesadaran warga bangsa dan berpengaruh dalam konstruksi nilai individu Indonesia. Tulisan ini berisi kajian tentang konsep, akar dan implikasi dari kemanusiaan dalam falsafah hidup masyarakat Batak Toba, Sumatera Utara.
Pemahaman ini bermanfaat bagi pengembangan daerah dan pembangunan nasional. Dewasa ini, di mana arus desentralisasi dan otonomisasi berkembang dengan kuat, daerahdaerah dituntut untuk menemukan kebajikankebajikan lokal dalam upaya penyelesaian berbagai persoalan dan merangsang pembangunan peradaban masyarakat yang lebih bermartabat (Latif, 2011, hal. 257). Kearifan-kearifan ini juga dapat menjadi tawaran bagi daerah-daerah lain bahkan masyarakat global dalam kesadaran tentang nilainilai kemanusiaan untuk mengatasi berbagai konflik sosial serta mengembangkan kebijakan pembangunan yang bermartabat (Latif, 2011, hal. 258).

Kemanusiaan telah ditetapkan sebagai sila kedua Pancasila. Kemanusiaan pada awalnya menggunakan istilah internasionalisme (Darmaputra, 1992, hal. 105). Muhamad Hatta (Latif, 2011, hal. 113), mengatakan bahwa sila kemanusiaan memiliki konsekuensi ke dalam dan keluar. Konsekuensi ke dalam dari sila kedua adalah kemanusiaan harus menjadi pedoman bagi negara dalam memuliakan hak-hak dasar warga negara, dalam menjalankan fungsi perlindungan terhadap warga negara, serta memajukan 
kesejahteraan umum dan mencerdaskan kehidupan bangsa; sedangkan konsekuensi keluar adalah negara harus ikut serta dalam perdamaian dunia, yang berdasarkan kemerdekaan, perdamaian abadi dan keadialan sosial.

Sila kemanusiaan telah memberi terang bagi negara, dalam jatuh bangun kesadaran, untuk berjuang menghargai kemanusiaan, memperjuangkan hak-hak asasi dan kehidupan yang layak bagi rakyat, solidaritas dengan yang lemah, serta sistem pemerintahan yang demokratis. Kesadaran tentang kemanusiaan juga telah mendasari sikap politik luar negeri ini yang bebas aktif, yang terimplementasi dalam sikap netral negara dalam berbagai konflik antar bangsa, menginisiator pembentukan gerakan non blok, serta tidak mengambil keuntungan dari pergolakan politik internasional (Latif, 2011, hal. 115).

Menelusuri catatan sejarah bangsa, terlihat bahwa kesadaraan tentang kemanusiaan tidak muncul seketika saat perumusan dasar negara atau hanya sekedar mengadopsi pemikiran-pemikiran Barat seperti yang dikatakan oleh Van Der Kroef (Darmaputra, 1992, hal. 126). Prinsip kemanusiaan, jauh sebelum ditetapkan sebagai dasar negara, telah dikumandangkan oleh para tokoh negeri ini. Contoh yang dapat kemukakan, Bung Hatta, pada pidatonya di Deen Haag, 9 Maret 1828 telah menegaskan prinsip kesamaan antar bangsa. Sang proklamator ini mengkritik sikap superioritas Eropa yang mengimperium Asia dengan alasan perbedaan derajat antar bangsa. Dalam sejarah, kesadaran tentang kemanusiaan masyarakat negeri ini muncul bersamaan dengan egalitarianisme dalam gelora nasionalisme untuk melawan penjajah (Latif, 2011, hal. 138). Semangat nasionalisme lahir dari kesadaran mengenai kesamaan kemanusiaan, sehingga melahirkan nasionalisme negeri ini men-jadi suatu nasionalisme yang berperikemanusiaan.

Prinsip kemanusiaan, hendak menegaskan bahwa seorang harus dipandang sebagai manusia, human being (Latif, 2011, hal. 219) dan menegaskan kepemilikan hak kodrati untuk hidup, bebas dan kepemilikan (Hernandes dalam Latif, 2011, hal. 219). Kesadaran ini telah mendasari kebijakan pemerintah untuk meratifikasi instrumen-instrumen HAM internasional, pembentukan institusiinstitusi penegakan HAM dan pengusutan pelanggaran HAM masa lalu.

Kesadaran tentang kemanusiaan di negeri ini bersumber dari keyakinan religius masyarakat (Kaelan, 2002, hal. 160). Hal ini berbeda dengan cara berpikir Barat yang lebih mendasarkan pada pemikiran filosofis ontologis. Prinsip ketuhanan yang mendahului kemanusiaan dalam hirarki nilai Pancasila jelas menegaskan aspek religius yang mendasari kemanusiaan. Prinsip kemanusiaan lahir dari keyakinan bahwa setiap orang diciptakan Tuhan dengan martabat yang luhur. Notonagoro (1975, hal. 89) mengatakan bahwa sila kemanusiaan yang adil dan beradab diliputi dan dijiwai oleh sila Ketuhanan yang Mahaesa, meliputi dan menyemangati sila persatuan Indonesia, kerakyatan dan demokrasi, serta perwujudan keadilan sosial bagi seluruh masyarakat.

Rumusan sila-sila Pancasila memang menggunakan term-term filsafat barat (Darmaputra, 1992, hal. 126). Hal ini dapat dimengerti sebab tokoh-tokoh perumus Pancasila dididik dalam struktur berpikir barat, akan tetapi substansi dasar dari sila-sila Pancasila bukan hasil adopsi dari pemikiran Barat. Presiden Soekarno pada pidatonya dalam Sidang Umum Perserikatan Bangsa-bangsa, 30 September 1960, menegaskan bahwa sila-sila Pancasila sudah terkandung dalam kebudayaan nusantara sejak ribuan tahun yang lalu sebelum imperialisme menenggelamkan RI (Latif, 2011, hal. 212). Orang Indonesia memang tidak mengenal istilah ketuhanan, tetapi mereka menghayati yang ilahi sebagai yang menyelimuti, meresapi, menyelenggarakan bahkan menentukan kehidupan (Zoetmulder, 1990, hal. 287-294). Berangkat dari pemikiran ini, pemahaman tentang hakikat dari nilai-nilai akan lebih mendalam dan diperkaya jika kita menelusuri penghayatan dan kesadaran tentang nilai-nilai Pancasila pada berbagai kebudayaan nusantara.

\section{METODE}

Kajian ini didasarkan pada pertanyaan dasar, apa konsep kemanusiaan dalam masyarakat Batak Toba; apa yang mendasari konsep kemanusiaan; dan apa implikasi dalam keseharian hidup. Kajian ini didasarkan pengalaman berada di tengah komunitas orang Toba sejak tahun 2001 sampai 2018. Peneliti, dalam kurung waktu tujuh belas tahun telah menyimak percakapan-percakapan, mengamati dan menyelami ritual-ritual adat serta mengalami dinamika hidup masyarakat Batak Toba. Pengalaman ini membawa kesadaran peneliti tentang nilai-nilai kemanusiaan orang Batak Toba yang tersembunyi di balik tuturan, aturan, prinsip hidup, etika dan ritual-ritual adat mereka.

Peneliti melakukan wawancara secara mendalam terhadap tiga tokoh adat Batak Toba, yakni Bapak Saut Gultom, Bapak J. Pandiangan dan Bapak Wilopo Hutapea periode April-Mei 2016. Data-data yang diperoleh didalami dengan membandingkan antar elemen data dan berbagai tulisan para peneliti sebelumnya tentang kebudayaan Batak Toba. 


\section{HASIL DAN PEMBAHASAN}

Kajian ini terfokus pada kesadaran tentang nilai kemanusiaan dalam kesadaran masyarakat Batak Toba. Pilihan objek material ini didasarkan pada pertimbangan bahwa suku Batak Toba memiliki pandangan khas tentang kemanusiaan. Batak Toba merupakan salah satu dari lima suku Batak. Istilah Batak Toba muncul karena kebanyakan polulasi suku ini mendiami sekitar Danau Toba; juga disebut halak Samosir atau orang Samosir karena leluhur mereka berasal dari pulau Samosir yang terletak di tengah Danau Toba. Zaman kolonial Belanda, suku Toba sering disebut dengan Batak Barat untuk menegaskan keberadaan mereka di sebelah Barat Danau Toba, yang dilawankan dengan masyarakat Simalungun yang mendiami wilayah Timur Danau Toba (Antono \& Purnomo, 2003, hal. 7). Suku Batak Toba, sekarang merupakan populasi terbanyak dari suku-suku Batak yang lain.

Apa pandangan orang Toba tentang kemanusiaan. Tulisan tentang kebudayaan orang Toba memang sudah cukup banyak, namun belum ada yang membicarakan secara khusus tentang kemanusiaan. Jalan untuk menemukan kesadaran ini, seperti yang dikatakan oleh Steeman adalah menyelami mitos-mitos, ritus-ritus, dan etika hidup orang Toba (Darmaputra, 1992, hal. 65). Mitosmitos seringkali menggambarkan pemahaman diri dan keberadaan dalam kosmos. Gambaran ini dirayakan secara ekspresif dalam ritus-ritus, dan dirumuskan serta dipraktekan dalam etika hidup (Darmaputra, 1992, hal. 65). Lewat ketiga jalur itu dapat diperoleh artikulasi kognitif, ekspresif serta praktis religius mereka.

\section{Bersumber dari pemahaman tentang manusia rajawi}

Kesadaran orang Toba tentang kemanusiaan paling tampak dalam pemahaman mereka tentang manusia rajawi. Pemahaman ini terungkap dalam berbagai sapaan, seperti raja nami (raja kami), amang raja (bapak raja), opung raja (kakek raja), anakni raja (anak raja), boruni raja (putri raja), rajani hula-hula (raja pemberi perempuan), rajani boru (raja pihak penerima perempuan), rajani dongan tubu (raja semarga), dan rajani huta (raja kampung). Kesadaran tentang martabat rajawi berakar dalam kosmologi teologis, membentuk jati diri, terikat dalam sistem kekerabatan dan norma adat, dan diimplementasikan menjadi nilai-nilai perjuangan hidup.

\section{Berpijak pada keyakinan kosmologi religius}

Falsafah hidup orang Toba berpijak pada keyakinan kosmologi religius mereka. Kosmologi
Batak mengenal alam yang terbagi atas tiga banua, yakni banua ginjang atau dunia atas, banua tonga atau dunia tengah dan banua toru atau dunia bawah. Mitologi Batak menhisahkan bahwa banua ginjang dihuni oleh debata tertinggi Opung Mulajadi Nabolon, yang tinggal di langit ketujuh. Banua ginjang, selain dihuni oleh Opung Mulajadi Nabolon, juga ada Tuan Batara Guru Doli, Tuan Sorimangaraja, Tuan Papan tinggi dan debata Asiasi. Keempat debata ini tinggal di langit keenam. Para dewa ini adalah sumber berkat bagi manusia. Tuan Batara Guru Doli adalah pemberi berkat adat istiadat dan hukumhukum; Tuan Sorimangaraja adalah pemberi kesucian, pelindung ladang, kampung dan anakanak; Tuan Papan Tinggi adalah pemberi kekayaan dan umur panjang sekaligus sumber konflik dan peperangan; dan debata Asiasi adalah pemberi anugerah belaskasih (Nainggolan, 2014, hal. 27).

Banua tonga dihuni oleh manusia dari hasil perkawinan antara Debata Siboru Deak Parujar dengan Tuan Ruma Uhir Si Tuan Ruma Gorga yang datang dari banua ginjang. Leluhur orang Batak berasal dari putra pasangan ini, yakni Si Raja Ihat Manusia. Banua tonga, selain manusia, juga dihuni roh para leluhur, yang disebut dengan begu, sumangot dan sombahon (Nainggolan, 2014, hal. 3233). Banua tongga juga didiami para dewa yang merepresentasikan kekuatan Opung Mulajadi Nabolon, antara lain Nai Sorimala Matabun yang menanamkan pohon kehidupan untuk menghubungkan banua tongah dengan banua ginjang (Tubing, 1956, hal. 57, 60); debata Idup yang menolong pasangan suami istri untuk memperoleh keturunan, debata Boraspati Ni Tano yang memberi kesuburan, Boru Saniang Nata sebagai dewata air yang memberi rejeki dan perlindungan bagi para nelayan, dan debata Boru Namora sebagai pemberi angin (Nainggolan, 2014, hal. 24-25).

Orang Batak meyakini bahwa ketika seseorang meninggal, tondi atau roh yang bersangkutan menjadi begu atau simangot. Begu adalah status roh yang berada pada level terendah, hampir disetarakan dengan hantu. Keturunan yang masih hidup dapat menaikan stutus roh yang bersangkutan menjadi sombahon atau yang terhormat, dengan melakukan ritual penghormatan, mengokol holi (Nainggolan, 2014, hal. 29). Ritual mengokol holi, pihak keluarga menggali kembali tulang belulang leluhur, kemudian disimpan dalam tambak atau tugu. Leluhur, dengan menjadi sombahon, menjadi sumber berkat bagi keturunannya (Gultom, dalam wawancara 10 April 2016).

Banua toru atau dunia bawah di huni setansetan dan Naga Padoha yang menjadi personifikasi kekuatan jahat. Banua toru menjadi penyeimbang kekuatan Mulajadi Nabolon yang menguasai banua 
ginjang dan banua tonga. Banua toru juga terdapat kura kura raksasa yang menopang bumi dengan punggungnya (Nainggolan, 2014, hal. 33).

\section{Anakni raja dan boruni raja}

Mitologi di atas mengajarkan bahwa orang Toba memiliki asal usul ilahi. Leluhur orang Toba berasal dari banua ginjang, keturunan dari Dewata Si Raja Ihat Manisia, putra dari Siboru Deak Parujar dari hasil perkawinannya dengan Tuan Ruma UhirSi Tuan Ruma Gorga. Orang Batak Toba, sebagai keturunan dewata yang bergelar raja, memahami jari diri sebagai pribadi yang bermartabat rajawi. Identitas ini terangkum dalam gelar anakni raja atau putra raja dan boruni raja atau putri raja. Orang Toba meyakini bahwa Dewata Si Raja Ihat Manisia adalah awal mula generasi manusia, karena itu martabat rajawi ini menjangkau semua orang. Universalitas martabat rajawi ini ditegaskan dalam pepatah Toba, 'raja ni ro, raja ni jabu' atau raja yang datang dan raja juga yang menunggu (Gultom, dalam wawancara 10 April 2016).

Istilah raja, sekarang dikaitan dengan garis keturunan marga. Orang Batak Toba memberi gelar kehormatan raja kepada opung atau kakek dalam garis patrilineal yang menjadi peletak dasar suatu marga. Gelar kehormatan ini juga didasarkan pada kesadaran tentang asal usul ilahi. Gelar ini berimplikasi pada kesadaran tentang kepemilikan martabat rajawi dari keturunannya. Kesadaran ini ini berkembang menjadi bahasa formal dalam setiap ritual adat. Raja parhata atau juru bicara adat dan pihak-pihak yang berbicara selalu menyapa lawan bicara dengan raja nami atau raja kami (Gultom, dalam wawancara 17 April 2016).

Pemahaman terhadap martabat rajawi ini membuat orang Toba melihat diri dan pihak lain berada dalam derajat yang sama. Orang Toba mengharamkam feodalisme dan menolak polarisasi masyarakat dalam hierarki kasta. Hal ini berbeda dengan Batak Simalungun dan masyarakat Melayu yang sejak lama hidup dalam sistem kerajaan (Sumbayak, 2001, hal. 107). Orang Toba memang mengenal sejumlah raja, seperti Raja Sisingamangaraja, Raja Sidabutar, namun tokohtokoh itu bukanlah raja dalam sistem monarki. Mereka digelari raja kerena kharisma yang menggerakkan perjuangan masyarakat, termasuk penolakan terhadap imperialisme Barat dan misi Kristen awal (Kurris, 2010, hal. 19).

Martabat rajawi, di satu pihak mengikat orang Toba dalam sistem kekerabatan dan norma-norma adat, namun di sisi lain, memberi hak-hak kodrati yang tidak bisa diganggu gugat, kemerdekaan dalam mengembangkan diri, keleluasaan dalam membangun visi dan mengejar ambisi hidup.

\section{Panghayatan martabat rajawi dalam sistem kekerabatan}

Martabat rajawi mengikat orang Toba dalam sistem kekerabatan dan norma-norma adat. Orang Toba meyakini sakralitas sistem kekerabatan dan norma-norma adat karena bersumber dari Debata Batara Guru Doli. Pepatah Toba mengatakan bahwa orang batak mati dalam adat menegaskan keterikatan ini seumur hidup (Gultom, dalam wawancara 17 April 2016).

Sistem kekerabatan Batak dapat dirangkum dalam dalihan na tolu. Istilah dalihan na tolu dapat diterjemahkan dengan tiga tungku atau tiang penyangga kekerabatan. Ketiga tiang kekerabatan itu adalah hula hula, dongan tubu dan boru (Jansen, 2003, hal. 34-35). Orang Toba meyakini manfaat dari sistem kekerabatan ini. Si dua uli songon mangkaol dalihan, masak sipanganon huhut malum na ngalian, berpegang pada tiga tiang tungku akan memberi keuntuntungan yaitu memasak makanan sekaligus menghangatkan tubuh (Sihombing, 2000, hal. 72).

Hula-hula adalah kelompok orang yang dalam sistem kekerabatan berada di atas. Mereka adalah pihak pemberi perempuan. Termasuk dalam kelompok ini adalah paman dari pihak ibu, orang tua dan saudara pria dari pihak istri; serta dalam arti luas semua yang semarga bahkan marga-marga lain yang serumpun dengan mereka. Hula-hula diyakini sebagai instrumen pembawa berkat ilahi. Hula-hula dikenakan gelar debata na tarida atau Tuhan yang kelihatan (Sihombing, 2000, hal. 76), karena itu diposisikan sebagai raja, disomba atau dihormati dan segala nasehatnya harus didengarkan (Gultom, dalam wawancara 17 April 2016).

Dongan tubu atau dongan sabutuha adalah kelompok orang-orang yang berada pada posisi sejajar karena kasamaan dan keserumpunan marga. Untuk memelihara persaudaraan dengan saudara semarga, orang Batak memiliki kewajiban mengenal tarombo atau silsilah. Biasanya tarombo menjadi isi percakapan awal ketika orang Batak bertemu dengan teman semarga. Terhadap kelompok yang sejajar ini, harus manat yang berarti selalu berhati-hati agar terpelihara persaudaraan dan terhindar dari segala perseteruan. Dalam relasi dongan tubu, orang Toba memiliki prinsip tampubolon aek do mardongan sabutuha, yang berarti persaudaraan semarga bagaikan air yang meskipun terus menerus di potong akan tetap kembali bertemu. Tali papaut tali panggongan, taripar laut sai tinanda tarupa ni dongan, sekalipun menyeberangi laut kita tetap saja mengenal dongan sabutuha (Sihombing, 2000, hal. 74-75).

Boru adalah kelompok orang-orang yang berada dalam posisi kekerabatan di bawah. Mereka 
adalah pihak saudari dan anak perempuan dan keluarga mereka, serta yang semarga dengan suaminya. Terhadap pihak boru, orang wajib memanifestasikan berkat-berkat sang ilahi, menjadi wajah Tuhan bagi mereka, debata na tarida. Prinsip yang harus dipegang dalam relasi ini adalah elek yang berarti mengayomi, merangkul, mengasihi, mengambil hati dan memberkati (Sihombing, 2000, hal. 77-78); sebaliknya dari pihak boru harus memberi sombah. Pihak boru, pada pesta-pesta adat, berperan sebagai pelayan dan pemberi tumpak atau uang sumbangan.

Somba marhula-hula, elek marboru dan manat mardongan tubu merupakan tiga pilar penyangga kekerabatan, sekaligus dasar pendidikan karakter dan konstruksi nilai orang Toba. Tiga norma ini merupakan norma dasar yang bersifat tetap dalam sistem kekerabatan orang Toba. Sejak kanak-kanak, orang Batak memupuk batin untuk berkonformistis, dan setelah menikah terlibat penuh dengan segala hak dan kewajiban untuk mengisi norma-norma ini. Kualitas dalam menjalankan norma-norma ini menentukan kehormatan seseorang. Istilah orang Toba mati dalam adat ada benarnya, sebab di situ jati diri dalam relasi tiga dimensi itu direalisasikan (Gultom, dalam wawancara 17 April 2016).

\section{Dirayakan dalam ritual somba dan pasu- pasu}

Kosmologi religius Batak adalah kosmologi rahmati. Para dewata banua ginjang maupun banua tongah adalah sumber berkat. Berkat-berkat dari para dewa itu disimbolisasikan dalam berbagai ritual adat dan keagamaan tradisional, yang bisa diringkas dalam dua istilah, yakni somba dan pasupasu. Ritual somba adalah ritual penghormatan kepada sang ilahi, yang kehadiran-Nya direpresentasikan lewat hula-hula. Sedangkan ritual pasu-pasu adalah ritual berkat dari sang ilahi juga lewat instrumen hula-hula (Gultom, dalam wawancara 3 Mei 2016).

Pemahaman berkat dalam tradisi Toba dapat ditelusuri dari sarana-sarana berkat dalam ritual pasu-pasu, antara lain boras sipirnitondi, dengke, dan ulos. Ritual berkat, dalam pesta-pesta adat, juga dilakukan lewat gerakan-gerakan tor-tor atau tarian tradisional Batak. Berkat-berkat yang disimbolisasikan lewat ritual-ritual itu, secara ringkas adalah berkat keturunan, kesehatan, perlindungan, panjang umur dan kesuksesan hidup. Berkat-berkat yang sama juga diharapkan dalam ritual kelahiran dan kematian. Pemberian boras sipirnitondi dan pengulosan pada ritual kesek-kesek atau kelahiran anak dimaksudkan agar si mengalami anak bertumbuh dengan sehat, kuat, memperoleh kesuksesan dan banyak keturunan. Pengulosan pada ritual kematian juga merupakan simbol berkat bagi si mati dalam periode paska kehidupan dan bagi keturunannya dalam melanjutkan kehidupan (Gultom, dalam wawancara 3 Mei 2016).

\section{Horas sebagai orientasi hidup orang Batak}

Semua berkat dari para dewata terarah kepada kesejahteraan hidup. Hal ini terlihat dari penggunaan kata horas sebagai aklamasi pada setiap ritual doa dan pasu-pasu. Kata horas dapat diartikan semoga beroleh selamat dan damai sejahtera (Gultom, dalam wawancara 3 Mei 2016). Doa-doa dalam berbagai ritual selalu terarah pada perperolehan berkat bagi kesejahteraan hidup (Gultom, dalam wawancara 3 Mei 2016). Orang Toba cenderung memandang ke bawah atau kehidupan sekarang, dari pada ke atas atau dunia ilahi. Pandangan ke atas, dalam doa-doa bukan untuk menyatukan diri dengan dewata banua ginjang, tetapi untuk mendapatkan berkat-berkat bagi kehidupan di bumi. Penekanan memiliki latarbelakang keyakinan teologis soteriologis yang cenderung material. Orang Toba berkeyakinan bahwa hidup sesudah kematian identik dengan hidup sekarang, sehingga kemampuan material berpengaruh pada status arwah (Gultom, dalam wawancara 3 Mei 2016).

\section{Direduksi dalam nilai hamoraon, hagabeon dan hasangapon}

Kebanyakan orang mereduksi pencapaian kesejahteran hidup pada tiga nilai dasar, yaitu hamoraon, hagabeon dan hasangapon. Hamoraon dapat diterjemahkan dengan perolehan kekayaan (Gultom, dalam wawancara 17 Mei 2016). Orang Toba berkeyakinan bahwa kekayaan adalah tanda berkat dari debata. Pemahaman ini memberi semangat perjuangan orang-orang Toba untuk membebaskan diri kemiskinan (Gultom, dalam wawancara 17 Mei 2016).

Hasangapon dapat diterjemahkan dengan kemuliaan, kewibawaan dan kehormatan. Nilai ini mendorong orang Batak untuk berjuang meraih jabatan dan kedudukan yang menghasilkan kesejahteraan, kehormatan atau kewibawaan sosial.

Hagabeon dapat diterjemahkan dengan keturunan. Orang Batak tradisional bercita-cita memiliki banyak keturunan. Umpasa atau pepatah Toba yang disampaikan pada ritual pernikahan menegaskan hal ini, gadu-gaduni silindung, tu gadu-gadu ni sipoholon, sai tubu ma anakmuna 17 dohot borumuna 16, yang berisi pengharapan agar kelak pengantin baru dikaruniakan 17 putra dan 16 putri (Gultom, dalam wawancara 17 Mei 2016). Mengalir dari nilai ini adalah nilai panjang umur, saur matua bulung, seperti daun yang gugur setelah tua. 
Hagabeon merupakan nilai tertinggi (Gultom, dalam wawancara 3 Mei 2016). Orang Toba melihat, kehadiran anak, terutama anak laki-laki melebihi segala nilai lain. Kehadiran anak menjamin kelanjutan generasi dan perolehen hak-hak dalam adat. Kehadiran anak memberi kehormatan dan gelar baru kepada orang tua. Mereka memperoleh gelar baru sebagai amang dan inang, ayah dan ibu dari si anak. Hal yang sama terjadi dengan pahopu atau cucu, sang opung (kakek dan nenek) memperoleh gelar baru sebagai opung doli dan opung boru (Gultom, dalam wawancara 17 Mei 2016). Hagabeon, dengan demikian mendasari dan menjiwai hamoraon dan hasangapon, bahkan semua nilai lain. Penghayatan ini menyebabkan pasangan suami istri yang tidak memiliki anak merasakan aib dalam perkawinan mereka. Perkawinan bernilai tinggi, namun perceraian dimungkinkan, bagkan kadangkala diharuskan oleh pihak keluarga bagi perkawinan yang tidak memperoleh anak. Zaman dahulu, demi memperoleh anak, orang menghalalkan pinjam jago demi memperoleh anak. Adik pria sang suami secara diam-diam diijinkan meniduri istri sang abang supaya sang abang mempeoleh keturunan dari darah yang sama (Gultom, dalam wawancara 17 April 2016). Cara ini, zaman sekarang telah ditinggalkan. Pasangan yang tidak memperoleh keturunan kebanyakan mengadopsi anak

Pencapaian nilai-nilai ini mengharuskan penggunaan akal budi dan strategi. Ungkapan bahwa orang Batak itu banyak taktiknya ada benarnya. Orang Batak kebanyakan gigih dan menggunakan banyak cara untuk mewujudkan hamoraon, hasangapon dan hagebeon. Pekerjaan sebagai guru, pegawai, pengusaha, alim ulama dinilai baik, namun sebagai mafia, calo dan preman juga dapat bernilai baik apabila merealisasikan nilai-nilai itu. Pihak yang menikmati keuntungan dari profesi itu bahkan memandangnya sebagai pahlawan (Gultom dalam wawancara 16 April 2016). Memberi kesempatan mandok hata atau menyampaikan kata sambutan sama artinya memberi kehormatan. Kegiatan pelelangan dan pesta merupakan jalan pengumpulan dana paling dapat diterima, sebab sang penyumbang memperoleh kehormatan.

Horas berarti pemenuhan ketiga nilai dasar itu, meskipun pencapaian horas membutuhkan nilainilai pendukung seperti nilai-nilai sosial, religius dan sebagainya.

\section{Halak asing menjadi halak kita}

Kesadaran orang Toba tentang kemanusiaan bisa ditelusuri juga dari pemahaman tentang halak kita dan halak asing (orang kita dan orang lain). Tidak ada norma yang tegas berkaitan dengan aspek ini, tetapi orang Toba memiliki sikap yang khas terhadap halak kita dari halak asing. Sikap ini lahir dari keterikatan yang kuat dalam sistem kekerabatan. Sistem daiana tolu membuat semua orang Batak berada dalam persaudaraan dan solidaritas keluarga besar. Ikatan ini menimbulkan efek pada mereka yang berada di luar kekerabatan. Orang-orang yang tidak terikat pada sistem ini disebut sebagai halak asing (Gultom, dalam wawancara 16 April 2016).

Harus diakui bahwa martabat rajawi orang Toba memberi pemahaman superioritas diri, namun demikian halak asing juga tidak dianggap lebih rendah. Orang Toba biasanya menuntut diprioritaskan dalam perolehan hak, namun di sisi lain hak halak asing juga dihargai. Halak asing memang dianggap orang luar dalam sistem kekerabatan Toba, tetapi halak asing juga bukan musuh, tidak lebih rendah dan dihargai sebagaimana adanya. Orang Toba memang tidak terlalu memelihara hubungan emosional dengan halak asing, tetapi juga tidak membenarkan penggerusan hak halak asing.

Fenomena menarik pada kehidupan orang Toba zaman sekarang adalah penambalan marga. Halak asing, karena kedekatan relasi ditambalkan marga tertentu sehingga menjadi halak kita dan terikat dalam sistem kekerabatan. Penambalan marga, bagi orang Toba merupakan bentuk solidaritas terdalam pada sistem kekerabatan. Penambalan marga membuat yang bersangkutan bukan lagi orang asing tetapi menjadi keluarga, semarga dan terikat dalam kerabatan, dengan segala hak dan kewajiban sebagai anakni raja dan boruni raja, amang raja dan inang soripada.

Penambalan marga tidak hanya terjadi orang yang masih hidup dan berjabatan. Beberapa daerah, mayat yang tidak dikenal asul usulnya, diangkat menjadi anggota keluarga, dan dikebumikan layaknya orang Toba dalam sistem kekerabatan (Hutapea, dalam kesaksian, 10 Oktober 2013). Tindakan ini memperlihatkan suatu solidaritas kemanusiaan Toba terhadap orang-orang yang tidak berdaya.

Orang Batak Toba, selain penambalan marga, juga menggunakan istilah ale-ale, teman-teman atau sahabat terhadap halak asing. Pihak yang tidak terikat langsung dengan sistem kekerabatan ini menjadi teman dalam persahabatan. Ale-ale juga diundang dalam pesta-pesta, bahkan diberi ruang serta makanan khusus bagi yang muslim. Semua ini memperlihatkan bahwa bagi orang Toba, halak asing tidak semata-mata orang lain tetapi bagian dari kehidupan, serta kehadiran dan hak-haknya dihargai. 


\section{KESIMPULAN}

Penting untuk menegaskan beberapa hal sebagai kesimpulan sekaligus refleksi kritis tentang prinsip kemanusiaan orang Toba. Harus dikatakan bahwa falsafah kemanusiaan orang Toba merupakan kekayaan besar yang bisa memberi sumbangan bagi pengembangan peradaban bangsa dan dunia. Ada empat hal yang bisa diungkapkan pada bagian ini.

Pertama, martabat hidup rajawi. Menarik bahwa orang Toba memahami diri sebagai putraputri raja, anakni raja dan boruni raja. Sebagai keturunan raja, mereka mengklaim diri memiliki martabat rajawi. Martabat ini tidak hanya dimiliki oleh elite tertentu karena garis keturunan, darah biru, tetapi dimiliki oleh semua orang dari generasi Toba. Pemahaman ini menggambarkan kesadaran akan martabat luhur manusia. Setiap orang karena asal usulnya yang ilahi memiliki martabat ilahi dan rajawi, karena itu setiap orang, siapapun dia, apapun latar belakangnya, karena martabat rajawi, harus diperlakukan secara terhormat dan bermartabat.

Martabat rajawi membawa konsekuensi pada sikap solidaritas Batak. Zaman sekarang banyak orang Toba perkotaan memiliki pembantu rumah tangga, namun menarik bahwa mereka tidak memandang sang pembantu sebagai pelayan, tetapi sebagai bagian dari keluarga. Sebutan yang biasa dikenakan identik dengan sebutan kekerabatan, seperti anak boru, ito, namboru, opung dan sebagainya.

Orang Toba memang banyak perhitungan untuk memperoleh keuntungan, namun di sisi lain, mereka tidak ingin menyengsarakan orang lain. Jarang terdengar bahwa orang Batak memperlakukan sewenang-wenang terhadap pembantu rumah tangga. Hal ini bisa menjadi pencerahan bagi masyarakat moderen untuk memperlakukan kelompok ini tidak semata-mata sebagai pekerja rendah, tetapi sebagai bagian keluarga. Mereka adalah pribadi-pribadi bermartabat yang harus dihargai.

Kedua, keadilan sistem kekerabatan. Sistem kekerabatan Batak membedakan orang menurut posisinya sebagai hula-hula, dongan tubuh dan boru. Pembedaan ini tidak menempatkan satu kelompok berada di bawah dan kelompok lain berada di atas. Orang Toba tidak mau menjadi budak dan enggan memperbudak orang. Pihak boru dalam pesta dan ritual adat bertugas untuk melayani, namun pada gilirannya orang yang sama juga bisa menjadi hulahula yang berperan sebagai pembawa berkat. Sistem kekerabatan Batak berdiri di atas prinsip keadilan.
Kesuksesan ekonomi memang memberi rasa hormat, tetapi tidak menempatkan yang bersangkutan pada posisi di atas. Pihak yang kaya dalam suatu kesempatan berperan sebagai boru, harus tetap melayani, sebaliknya si miskin yang berperan sebagai hula-hula ia tetap harus dihormati sebagai penyalur berkat. Kesuksesan harus diraih tetapi tidak bisa menjadi dalih untuk menempatkan diri di atas yang lain. Kekerabatan memberi dampak pada keadilan sosial masyarakat.

Ketiga, tradisi penambalan marga, ale-ale, dan yang serupa dengan itu kiranya dapat menjadi jembatan untuk membangun persaudaraan universal. Sistem ini memungkinkan pihak luar sebagai saudara, keluarga dan sahabat. Persaudaraan universal akan melahirkan kasih, solidaritas dan perdamaian universal.

Keempat, keharusan realisasi hak-hak asasi manusia. Penggunaan kata horas dan orientasi pada kesejahteraan hidup hendak menegaskan hak setiap orang untuk memperoleh hidup yang layak. Nilai hamoraon, hagabeon dan hasangapon merupakan representasi dari nilai-nilai kemanusiaan yang mendasari hak-hak asasi manusia.

Harus dikatakan bahwa keempat kesadaran ini merupakan cahaya dari puncak bukit barisan bagi masyarakat dunia yang semakin individualistis dan egoistis. Di sisi lain, harus disadari bahwa falsafah kemanusiaan Toba juga tetap membutuhkan insight dari tatanan nilai objektif universal untuk membangun peradaban kemanusiaan yang lebih bermartabat.

Ada dua hal patut disebutkan dalam tulisan ini. Pertama, solidaritas dengan yang tidak berketurunan. Penekanan pada hagabeon menyebabkan orang Toba memandang anak dan keturunan sebagai segala-galanya, anakkonhido Hamoraon di au, anakku adalah kekayaanku. Prinsip ini pada sisi lain menimbulkan keprihatinan terhadap pasangan yang tidak memiliki keturunan. Mereka kehilangan banyak hak dalam adat. Kebanyakan pasangan seperti ini menjadi rendah diri dan merasa gagal dalam hidup. Jalan adopsi tidak mudah dilakukan oleh pasangan yang berekonomi lemah. Terlepas dari siasat positif yang bisa ditempuh oleh pasangan demikian, filosofi hagabeon tetap harus disempurnakan dengan dengan prinsip kemanusiaan universal. Pasangan yang tidak memiliki keturunan tetap harus diberi tempat dan kehormatan yang sama.

Kedua, kecenderungan untuk korupsi, kolusi dan nepotisme (KKN) demi kekerabatan. Kekuatan kekerabatan seringkali membawa orang Batak Toba merelatifisir nilai-nilai lain, seperti kejujuran, keadilan dan sebagainya. Demi keluarga dan kerabat, orang Toba rela melakukan korupsi, kolusi 
dan nepotisme. Memang orang Toba menjunjung tinggi kejujuran, keadilan dan nilai-nilai luhur yang lain, namun nilai ini bisa dikalahkan oleh kepentingan keluarga dan kekerabatan. KKN itu buruk, namun pada saat tertentu KKN dapat bernilai positif jika berhadapan dengan kepentingan anak atau kerabat. Relatifisir nilai dengan dasar kegunaan menunjukkan bahwa falsafat kemanusiaan orang Batak Toba membutuhkan pencerahan dari tata nilai objektif dan universal.

\section{DAFTAR PUSTAKA}

Antono, Y. S., \& Purnomo, A. B. (2003). Pengaruh kekristenan pada kebudayaan Simalungun: Etnografi dan refleksi teologis kontekstual. Pematangsiantar: Kolportase GKPS bekerja sama dengan Panitia Bolon Seratus Tahun Injil di Simalungun.

Darmaputra, E. (1992). Pancasila, identitas dan modernitas: Tinjauan etis dan budaya. Jakarta: BPK Gunung Mulia.

Jansen, A. D. (2003). Gondang Simalungun: Struktur dan fungsinya dalam masyarakat Simalungun. Medan: Bina Media Perintis.

Kaelan. (2002). Filsafat Pancasila: Pandangan hidup bangsa Indonesia. Yogyakarta: Paradigma.

Kurris, R. (2010). Pelangi di Bukit Barisan: Gereja katolik memasuki Tapanuli. Yogyakarta: Kanisius.

Latif, Y. (2011). Negara Paripurna: Historisitas, rasionalitas, dan aktualitas Pancasila. Jakarta: Gramedia Pustaka Utama.

Nainggolan, T. (2014). Batak Toba: Sejarah dan transformasi religi. Medan: Bina Media Perintis.

Notonagoro. (1975). Pancasila secara ilmiah populer. Jakarta: Pantjuran.

Sihombing, T. M. (2000). Filsafat Batak. Jakarta: Balai Pustaka.

Sumbayak, J. (2001). Refleksi Habonaron do Bona dalam Adat Budaya Simalungun. Pematangsiantar: Partuha Maujana Simalungun.

Tubing, P. L. (1956). The structure of the Batak Toba belief in the high God. Jakarta: South and Southeast Celebes Institute For Culture.

Zoetmulder, P. J. (1990). Manunggaling Kawulo Gusti: Pantheisme dan Monisme dalam Sastra Suluk Jawa. Jakarta: Gramedia Pustaka Utama.
Catatan:

Narasumber wawancara:

$\begin{array}{ll}\text { 1. Nama } & \text { : Saut Gultom } \\ \text { Usia } & \text { : 70 tahun } \\ \text { Pendidkan } & \text { : Diploma 2 } \\ \text { Pekerjaan } & \text { : Pensiunan guru } \\ \text { Kedudukan } & \text { : Raja perhata/tokoh adat } \\ \text { Batak Toba } & \\ \text { 2. Nama } & \text { : Wilopo Hutapea } \\ \text { Usia } & \text { : } 67 \text { tahun } \\ \text { Pendidikan } & \text { : S2 } \\ \text { Pekerjaan } & \text { : Komisi Keluarga KAM } \\ \text { Kedudukan } & \text { : Tokoh masyarakat } \\ \text { Nama } & \text { : J. Pandiangan } \\ \text { Usia } & \text { : 70 (telah meninggal akhir } \\ \text { 2016) } & \text { : SLTA } \\ \text { Pendidikan } & \text { : Bengkel } \\ \text { Pekerjaan } & \text { : Tokoh adat Batak Toba }\end{array}$

